\title{
Acesso da Comunidade Surda à Rede Básica de Saúde
}

\section{Deaf Community's Access to the Primary Health Care Network}

\author{
Aurea lanni \\ Doutora. Pesquisadora do Instituto de Saúde (IS), SES-SP. \\ Endereço: Rua Santo Antonio, 590, Bela Vista, CEP 01314-000, São \\ Paulo, SP, Brasil. \\ E-mail: aureanniळisaude-sp.gov.br \\ Patrícia Cristina Andrade Pereira \\ Mestra em Saúde Pública. Ex-aluna do curso de aprimoramento \\ do Instituto de Saúde (IS), SES-SP.
}

\section{Resumo}

Mediante o Decreto 5626/o5, os serviços de saúde devem atender diferenciadamente a Comunidade Surda, minoria sociolinguística e cultural, usuária da Língua de Sinais Brasileira (LIBRAS). 0 objetivo deste trabalho é apresentar as peculiaridades do acesso da população surda aos serviços de Atenção Básica e a percepção dos gerentes de unidades de saúde a esse respeito. Quanto aos métodos, o projeto foi realizado em duas etapas: na primeira (a fase exploratória), foram realizadas quatro entrevistas com informantes-chave pertencentes à Comunidade Surda e membros representativos do governo (dois usuários e dois administradores da Secretaria Municipal e Estadual de Saúde de SP); na segunda etapa, aplicou-se um questionário para 21 gerentes de Unidades Básicas de Saúde (UBS) de uma sub-regional do Município de São Paulo. Os resultados demonstraram dificuldades no acesso às UBS. Os gerentes das UBS demonstram perceber que a rede encontra-se em processo de mudança de paradigmas para a realização desse atendimento, deslocando-se do paradigma dos serviços para o paradigma de suporte, e também apresentam grande interesse por iniciativas relacionadas à área, necessitando de recursos para desenvolvê-las. Dessa forma, há um descompasso entre as determinações jurídicas, as expectativas dos pacientes Surdos e o que se pode oferecer, hoje, nas UBS. Tais fatos nos convidam a refletir sobre o tema, os próprios princípios do SUS e o desenvolvimento social brasileiro.

Palavras-chave: Comunidade surda; LIBRAS; Acesso; SUS; Atenção Básica de Saúde; Humanização e Direito dos Pacientes. 


\section{Abstract}

According to the decree 5626/05, the health services must differentially assist the Deaf Community, a sociolinguistic and cultural minority that uses the Brazilian Sign Language (LIBRAS). The objective of this study is to introduce the particularities of access of the Deaf population to the Primary Health Care services and the perception of the health unit managers about this matter. Regarding methods, the project was carried out in two steps. In the first step (exploratory), four interviews were conducted with key informers who belong to the deaf community and with representative members of the government (two users and two administrators of the State and Municipal Health Departments of São Paulo). In the second step, we administered a questionnaire to 21 managers of Primary Care Units (UBS) of one sub-district of the city of São Paulo. The results demonstrate difficulties in the access to the UBS and were categorized according to profile and causes. The UBS managers seem to realize that the network has been changing paradigms to provide such services, moving from the service paradigm to the support paradigm; in addition, they show great interest in initiatives related to the area, requiring only financial resources to develop them. Thus, there is a disagreement between the legal decisions, the expectations of the deaf community and what can be currently offered by the Health System. Such facts invite us to reflect upon the topic, the principles of SUS (Brazil's National Health System) and the Brazilian social development.

Keywords: Deaf Community; LIBRAS; Access; Brazil's National Health System (SUS); Primary Health Care; Humanization and Patients' rights.

\section{Introdução}

O capítulo VII do Decreto de Lei ${ }^{0} 5626$, de 22 de dezembro de 2005 (Brasil, 2005), que trata da "garantia do direito à saúde das pessoas Surdas ou com deficiência auditiva”, determina que, a partir de 2006, o atendimento às pessoas Surdas ou com deficiência auditiva na rede de serviços do Sistema Único de Saúde (SUS), bem como nas empresas que detêm concessão ou permissão de serviços públicos de assistência à saúde, seja realizado por profissionais capacitados para o uso de Língua de Sinais Brasileira (LIBRAS) ou para a sua tradução e interpretação. O reconhecimento da Comunidade Surda como minoria sociolinguística e cultural apresenta-se como importante desafio para o SUS, tanto no que remete à identificação de suas especificidades psicolinguísticas quanto no que diz respeito aos desafios linguísticos que, até então, referenciavam essa população aos níveis secundário e terciário de atenção à saúde.

\section{Objetivos}

Apresentar as dificuldades do acesso da população surda aos serviços de Atenção Básica e a percepção dos gerentes de unidades de saúde a esse respeito.

\section{Métodos}

O projeto foi aprovado pelo Comitê de Ética da Secretaria Municipal de Saúde de São Paulo. Na primeira fase (exploratória), as quatro entrevistas com informantes-chave foram filmadas e, quando em LIBRAS, além de transcritas também foram traduzidas para o português. 0 primeiro entrevistado era ouvinte e responsável legal por uma criança surda; o segundo era uma liderança da Comunidade Surda. Os outros dois entrevistados eram membros representativos do governo, administradores da Secretaria Municipal de São Paulo e da Secretaria de Estado da Saúde de São Paulo, respectivamente. Para a realização da segunda etapa, aplicou-se presencialmente um questionário para 21 gerentes de Unidades Básicas de Saúde (UBS) de uma sub-regional do Município de São Paulo. O questionário foi confeccionado em três partes. Algumas perguntas objetivavam a identificação da Unidade de Saúde; outras, o perfil dos profissionais; e, por último, propunha-se perguntas específicas relacionadas ao atendimento dos pacientes surdos. 


\section{Resultados}

Apresentam-se, a seguir, os resultados obtidos a partir das entrevistas realizadas com os informantes-chave, utilizando-se material confeccionado por um Surdo adulto e a compilação da legislação vigente. 0 material foi analisado e sistematizado segundo as queixas/problemas referentes ao acesso da Comunidade Surda ao funcionamento organizacional dos serviços de saúde. Essas queixas foram agrupadas segundo categorias relativas às barreiras comunicacionais, às políticas públicas direcionadas para a Comunidade Surda e às queixas consideradas 'inespecíficas' (aqui, incluemse aquelas relativas aos serviços de saúde, que dizem respeito à estrutura dos mesmos e atingem toda a população).

Nesta etapa inicial do projeto, pode-se resumir os seguintes aspectos relacionados ao acesso:

- Barreiras Comunicacionais: dificuldades na marcação de consulta por telefone, ausência de intérprete, surdo confundido com deficiente mental, falta de língua em comum, falta de paciência.

- Insumos Tecnológicos: escassez de Aparelhos de Amplificação Sonora Individuais (AASI), Telefones para surdos (TDD), poucas adaptações no uso de iluminação, celulares, e-mails e fax, e falta de meios comunicativos visuais.

- Políticas Públicas: escassez de profissionais para reabilitação - a Secretaria de Educação era porta de entrada para a Saúde, mas sabe-se que a grande maioria da população surda está excluída da escola. Ausência de legendas em campanhas, políticas ouvintizadoras, políticas assistenciais: Lei Orgânica da Assistência Social (LOAS), gratuidade de transporte, fila preferencial, falta de serviços.

- Queixas inespecíficas: má vontade do profissional, atendimento de baixa qualidade, dificuldades socioeconômicas.

Também foram categorizadas as possíveis causas dessas dificuldades, respectivamente:

A. Recursos Humanos - falta de capacitação dos funcionários para o atendimento dessa população e para o uso de insumos tecnológicos, além da ausência de intérpretes;

B. Políticas compensatórias / assistencialistas;

C. Educação versus Saúde (referência e contrarreferência, Centros Especializados).
Na segunda etapa da pesquisa, dos 21 gerentes apenas 12 responderam ao questionário específico. Os principais resultados são apresentados sucintamente no quadro a seguir.

Os gerentes das UBS desta subárea de saúde de São Paulo demonstram desconforto com o tema, o que justifica a baixa adesão à terceira fase do questionário. Percebem que a rede encontra-se em processo de mudança de paradigmas para a realização desse atendimento, deslocando-se do paradigma dos serviços para o paradigma de suporte, e também apresentam grande interesse por iniciativas relacionadas à área, necessitando de recursos para desenvolvê-las.

\section{Considerações Finais}

Segundo Aranha (1980) e Pessoti (1984), as pessoas com deficiência, na Antiguidade, eram abandonadas ao relento até a morte. Na Idade Média, a filosofia cristã incutia a ideia de que a pessoa com deficiência não teria alma. A deficiência era ora desígnios divinos, ora possessão do demônio. A Igreja controlava seus fiéis a partir da concepção de que a deficiência seria um castigo vindo dos céus. Com a formação dos Estados Modernos, há uma nova divisão dos processos produtivos e os recursos humanos, até então desconsiderados, passam a ser vistos como força de trabalho; mas essa lógica não atingia o grupo de deficientes, que permaneceu sendo visto como grupo não produtivo. Na mesma época, a problemática da deficiência era escopo não apenas dos estudos teológicos e relativos à moralidade, mas também da Medicina. Os primeiros 'tratamentos' propunham a Institucionalização dessa população, que não era mais sacrificada após o nascimento, mas confinada em Hospitais Psiquiátricos, Dispensários, também denominados de Instituições Totais [paradigma da institucionalização]. A não produtividade continuava a ser valorada negativamente. Somente em meados do século XX é que se passa a considerar a "integração social das minorias", em resposta ao pós-guerra. 0 [paradigma dos serviços] assume a defesa dos direitos do cidadão. A Institucionalização e a 'normalização' são questionadas e suplantadas por modelos assistenciais em que cabe à sociedade oferecer os serviços que os cidadãos com deficiência têm direito. Os custos para a sustentação desse modelo parecem ter motivado a revisão desses conceitos. Surge, então, 


\section{Quadro I - Resultados do Questionário Específico}

\begin{tabular}{|c|c|c|}
\hline UBS/ Atendimento aos surdos & Atendem [9] & Não atendem [3] \\
\hline Número de Surdos Atendidos & 2 a 10 pessoas & 0 \\
\hline Como /por que & $\begin{array}{l}\text { - Através de oficinas, orientação à família e pessoa / individual e em grupo; } \\
\text { - Recepção foi treinada em I99ı; } \\
\text { - Quando são procurados; } \\
\text { - Atende como as outras pessoas; } \\
\text { - Fala olhando para o cliente e usa gestos, fala pausada, leitura labial do } \\
\text { próprio paciente por escrito, funcionária que tem parente que usa LIBRAS; } \\
\text { - Acompanhante / familiares. }\end{array}$ & --- \\
\hline $\begin{array}{l}\text { Procedimentos no atendimento } \\
\text { (referência/ contrarreferência) }\end{array}$ & $\begin{array}{l}\text { - Todos são capacitados (usuários com Deficiência Auditiva) para leitura } \\
\text { labial; } \\
\text { - Interface com a educação, assistência social, cultura etc., onde orienta e } \\
\text { faz ações voltadas para o segmento de deficientes também; } \\
\text { - Tem uma agente de saúde que conhece a linguagem dos sinais; } \\
\text { - Atende normal, com mais atenção a este cliente; } \\
\text { - Faz a recepção e a orientação do paciente que tem direito ao benefício; } \\
\text { caso não tenha audiometria recente, encaminha ao ambulatório; } \\
\text { - Não informaram. }\end{array}$ & -- \\
\hline $\begin{array}{l}\text { Meios de Comunicação } \\
\text { Especificos na interação com o } \\
\text { Surdo }\end{array}$ & $\begin{array}{l}\text { - Leitura labial, fala pausada e direcionada; } \\
\text { - Sinais das mãos; } \\
\text { - Escrita; } \\
\text { - Através do acompanhante ou profissional; } \\
\text { - Não informaram. }\end{array}$ & $\begin{array}{l}\text { - Gestual e leitura } \\
\text { de lábios. }\end{array}$ \\
\hline $\begin{array}{l}\text { Atividades/ serviços/ programas } \\
\text { desenvolvidas para o Surdo }\end{array}$ & $\begin{array}{l}\text { - Nenhum tipo de atividade / serviço / programa especializado; } \\
\text { - Não informaram. }\end{array}$ & \\
\hline $\begin{array}{l}\text { Estratégias para melhorias do } \\
\text { atendimento da Comunidade }\end{array}$ & $\begin{array}{l}\text { - Cursos de LIBRAS, orientações e educação continuada, investimentos em } \\
\text { tecnologia e arquitetura para acessibilidade; } \\
\text { - Treinamento para os profissionais da rede; } \\
\text { - Não sei, gostaria de saber de outras experiências. }\end{array}$ & $\begin{array}{l}\text { - Treinamento em } \\
\text { linguagem de } \\
\text { sinais; } \\
\text { - Não informaram. }\end{array}$ \\
\hline
\end{tabular}

o terceiro e último paradigma, o [paradigma do suporte]. A partir deste, disponibiliza-se ao cidadão com deficiência apoios que se mostrem necessários para a otimização de seu potencial pleno no que se refere às estratégias, ações e/ou tecnologias. A análise dos dados demonstrou que a rede de atenção básica de Saúde situa-se entre os paradigmas [institucionalizante] e de [serviço]. Os gerentes das Unidades Básicas de Saúde, no entanto, apesar de não terem demonstrado ciência exata dos caminhos a serem traçados, demonstram reconhecer o lapso apresentado na problematização do tema e mostram-se consonantes com a tendência dos futuros meios para a Promoção do Acesso da Comunidade Surda à rede de atenção Básica de Saúde [os paradigmas de suporte].

\section{Referências}

\author{
ARANHA, M. Review of the REHABILITATION \\ MOVEMENT in the United States and proposals \\ for an extended rehabilitation model in Brazil. \\ 1980. Dissertation. Southern Illinois University, \\ Carbondale, Ill, 1980.
}

BRASIL. Ministério da Saúde. Decreto 5626/o5 que regulamenta a Lei ${ }^{0} 10436$ de 24 de abril de 2002. Brasília: Ministério da Saúde, 2005. Disponível em:<HTTP://www8.pr.gov.br/portals/portal/ institucional/dee/legislacao/lf_dec5626_2005.pdf >. Acesso em: 14 fev. 2007.

PESSOTTI, I. Deficiência mental: da superstição à ciência. São Paulo: T. A Queiroz, 1984. 